\title{
NUEVAS APORTACIONES SOBRE LAS MURALLAS Y EL SISTEMA DEFENSIVO DE SANTA FE (GRANADA) $^{1}$
}

\author{
POR \\ LUIS JOSÉ GARCÍA PULIDO \\ $\mathrm{y}$ \\ ANTONIO ORIHUELA UZAL
}

\begin{abstract}
La Granada nazarí fue rendida mediante una larga guerra de desgaste. Para culminar esta empresa, los Reyes Católicos establecieron a lo largo de 1491 a todos sus efectivos en la vega granadina, alojando a este contingente de tropas y bastimentos en las tiendas y chozas de un campamento militar, el Real de la Vega. Inmediatamente se iniciaron las obras de construcción de una ciudad-campamento para poder albergar una guarnición de invierno, el Real de Santa Fe, donde se introdujeron algunas de las innovaciones propias de la fortificación española de transición de la época medieval a la moderna. Este artículo trata de desvelar cómo fueron protegidos estos dos reales y cuáles fueron sus elementos más significativos, tomando como base los datos contenidos en el relieve de la sillería del coro bajo de la Catedral de Toledo en el que se representan estos acontecimientos ${ }^{2}$.

Palabras clave: Santa Fe; Guerra de Granada; 1491; 1492; murallas; fortificación; Reyes Católicos.

Nasrid Granada was conquered by means of a long, debilitating war. In order to culminate this undertaking, throughout 1491 Ferdinand and Isabella installed all of their troops in the plain of Granada, quartering them in the tents and huts of a military encampment, the Real de la Vega. Forthwith, the construction of a city-encampment was begun as a winter garrison, the Real de Santa Fe, where some of the innovations in Spanish fortification work -in transition from the medieval to the modern- were introduced. This text, by utilizing the data contained in the carved relief of the lower choir stalls of Toledo Cathedral in which these events are represented, attempts to reveal the most significant elements of these two royal camps and how they were protected.
\end{abstract}

Key words: Santa Fe; war of Granada; 1491; 1492; walls; fortifications; Ferdinand and Isabella.

Santa Fe representa un hito en la historia por innumerables motivos de sobra conocidos. Ciudad entre mundos; surgida para rendir a la Granada nazarí y, a la postre, convertida en modelo de las ciudades coloniales del recién descubierto territorio iberoamericano. Sin embar-

\footnotetext{
${ }^{1}$ El presente trabajo ha surgido dentro del marco de estudio que el Grupo de Investigación de Arquitectura Hispanomusulmana de la Escuela de Estudios Árabes de Granada (Consejo Superior de Investigaciones Científicas) viene realizando sobre los sistemas de fortificación defensiva con que contaron las ciudades enclavadas en el antiguo reino de Granada.

${ }^{2}$ Recientemente los autores han dado a conocer una novedosa interpretación de los datos contenidos en este tablero. García Pulido, Luis José y Orihuela Uzal, Antonio. «La imagen de Santa Fe (Granada) en la sillería del coro bajo de la Catedral de Toledo». Archivo Español de Arte, LXXVII, 2004, 307, pp. 247 a 266.
} 
go, subyace en su fundación un aspecto de enorme interés al que no se le ha prestado suficiente importancia, ya que, si a nivel urbano el devenir la convirtió en laboratorio de experimentación para asentar otras ciudades en el Nuevo Mundo, en lo referente a cuestiones defensivas podría situarse en el punto de inflexión definido por el paso de las fortificaciones medievales a las modernas, adaptadas al imparable desarrollo de los nuevos efectivos pirobalísticos. No por casualidad, el momento cronológico en el que surgió, el final de la larga y agónica Guerra de Granada, supuso también el final de los ejércitos y confrontaciones bélicas a la usanza medieval para entrar de lleno en el arte de la guerra de la época moderna.

\section{El REAl de la Vega}

«El rey assentó su real muy ordenadamente allí [en el Gozco], a par de donde edeficó la villa de Sancta Fee, dos leguas [11.145 m] de Granada, donde continuamente tobo más de cincuenta mill honbres de pelea, en que avía diez mill de caballo (...). Fizo el rey cercar el real muy bien, de paredes e cavas, como lo tenía por costumbre en los otros cercos. E desque el real fue fortalescido, la reina e el príncipe e la infanta doña Juana vinieron al real desde Alcalá la Real (...)» ${ }^{3}$.

El enclave en el que se situó el Real de la Vega era una zona bien conocida por las tropas cristianas. Un claro precedente de este asentamiento militar fue el campamento establecido por Juan II con motivo de la Batalla de la Higueruela, cuando, tras entrar el ejército castellano el 28 de junio de 1431 con sus huestes ordenadas en la Vega de Granada, se asentó el real en la orilla derecha del Genil, cerca de Atarfe. Todo el campamento se levantó firmemente en un solo día gracias al Condestable don Álvaro de Luna, como así lo testimonió su cronista: «Otro día, viernes, veynte e nueve días del mes de junio, dio el Condestable tan grand priesa que el real del Rey fue çercado de un gran palenque, muy bien ordenado. Sería la çerca del palenque de tanto compás como la çibdad de Sevilla. E mandó dexar en él quatro puertas, por do entrassen e saliesen en el real, que estaba ordenado por sus calles en muy fermoso asiento» ${ }^{4}$.

Por su parte, el rey Fernando el Católico frecuentó estas tierras desde casi el comienzo de la Guerra de Granada, pues ya el 21 de junio de 1483 "por la mañana, se asentó el Real á los ojos de Huetar [Huécar] (...)» (Fig. 1). El lunes y martes siguientes demandó el Rey «al secretario Francisco de Madrid que tomase á su cargo derribar la torre que dice de Huecar, que estaba Xenil ayuso, baxo del Real» ${ }^{5}$. Además, esta posición de los Ojos del Huécar (surgencia de agua que vendría a coincidir con la actual del Canal de los Ojos de Viana, localizada al noreste de Santa $\mathrm{Fe}$ ) fue elegida porque «Los moros no pudiendo resisitir la tala que veían fazer de sus frutos acordaron enturbiar el agua que yba por las azequias donde los cristianos se proveían de manera que la hueste no se podía aprovechar de ella. E por esta causa el Rey mandó mudar su real de aquel lugar e ponerlo cerca de unas fuentes que se llaman Ojos de Huécar, porque en mengua de agua la hueste no recibiera daño» ${ }^{6}$. Esta situación volvería a

\footnotetext{
${ }^{3}$ Bernáldez, Andrés. Memorias del reinado de los Reyes Católicos que escribía el bachiller Andrés Bernaldez, Cura de Los Palacios. Edición y estudio por Manuel Gómez-Moreno y Juan de Mata Carriazo y Arroquía. Madrid, 1962. pp. 224-232. Documento que reproduce Peinado Santaella, Rafael Gerardo. La fundación de Santa Fe (1491-1520). Granada, 1995. p. 326.

${ }^{4}$ Porras Arboledas, Pedro A. Juan II (1406-1454). Corona de España I. Reyes de Castilla y León. Palencia, 1995. p. 180.

${ }^{5}$ Relación de las cosas que pasaron en la entrada quel Rey nuestro Señor fizo en el reyno de Granada en el mes de Junio deste presente año (1483, según la Crónica del Marqués de Cádiz). Documento citado por Valladar, Francisco de Paula. Colón en Santafé y Granada. Estudio Histórico. Granada, 1892. p.38.

${ }^{6}$ Pulgar, Fernando del (ca. 1430-ca. 1493). Crónica de los Reyes Católicos por su secretario Fernando del Pulgar. Edición y estudio por Juan de Mata Carriazo y Arroquía. Madrid, 1943. Tomo II, Guerra de Granada. pp. 79-80. Documento citado por Lapresa Molina, Eladio. Santafe: Historia de una ciudad del siglo xv. Granada, 1979. p. 20 , nota 14.
}

$A E A$, LXXVIII, 2005, 309, pp. 23 a 43 

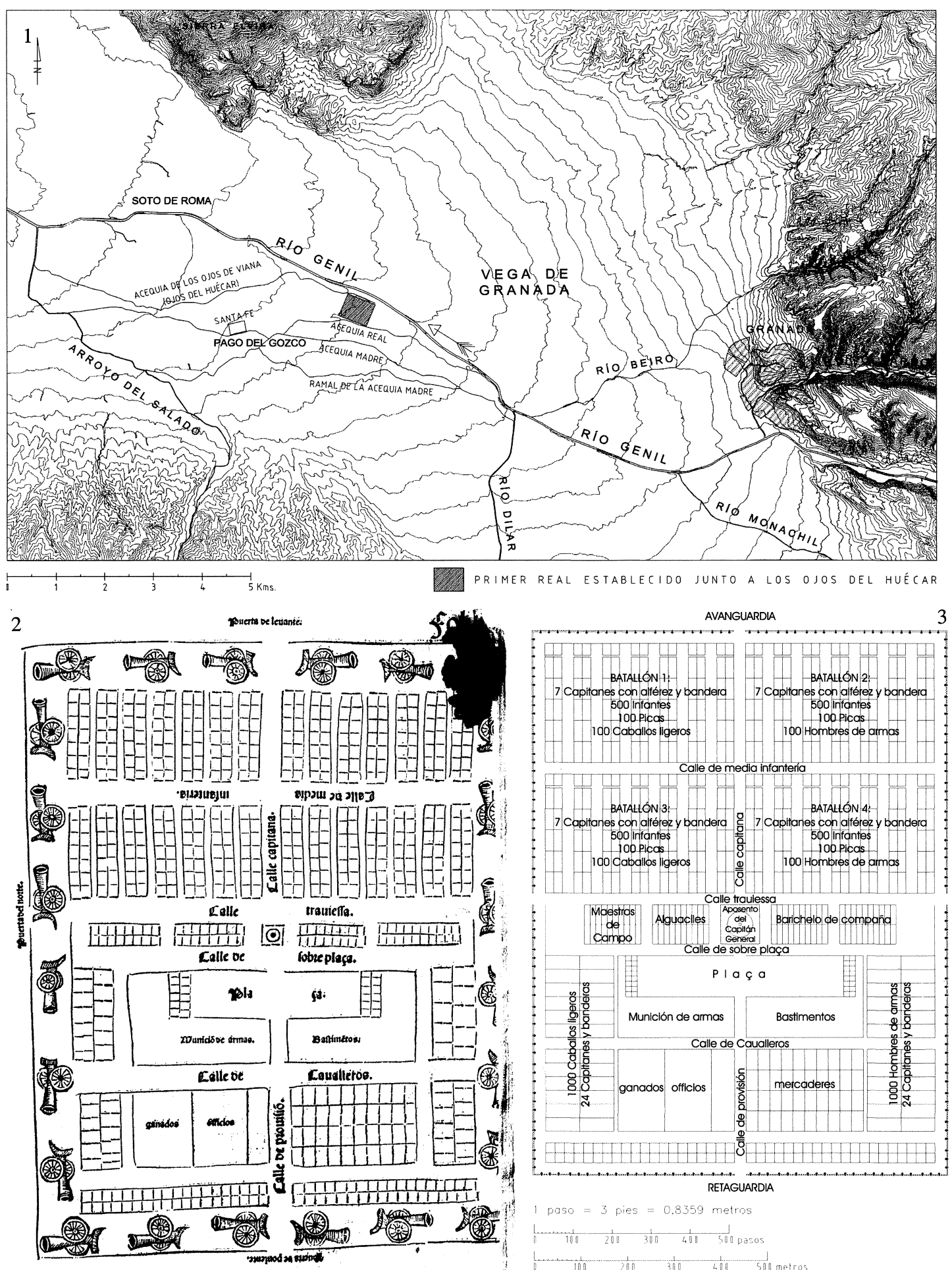

Fig. 1. Plano topográfico del sector de la Vega de Granada comprendido entre la capital y Santa Fe. En él se dibuja el emplazamiento hipotético del primer Real de las tropas cristianas junto a la Fuente de los Ojos del Huécar.

Fig. 2. Croquis del tipo de real utilizado por el Gran Capitán en sus campañas de Nápoles recogido en el Tratado de Re Militari de Diego de Salazar (1536), folio 52r.

Fig. 3. Interpretación a escala del croquis del real tipo utilizado por el Gran Capitán en sus campañas de Nápoles recogido en el Tratado de Re Militari de Diego de Salazar (1536).

$A E A$, LXXVIII, 2005, 309, pp. 23 a 43 
repetirse a lo largo de la campaña de 1486 en la que «(...) abiendo entrado en la vega hicieron un alto junto a una fuente que llamaban los moros los ojos de Guexar [Huécar] (...)» ${ }^{7}$, y en la de 1490, cuando durante una incursión castellana por estos pagos «(...) tomaron la torre de Roma, que está a dos leguas [11.145 m] de Granada (...)» ${ }^{8}$, torre que se ubicaba en el Soto de Roma, al noroeste de Santa Fe, junto al actual núcleo urbano de Romilla.

Finalmente, en los últimos días del mes de abril de 1491, partiendo Fernando el Católico desde Sevilla, entró en territorio nazarí tras pasar por las localidades de Alcalá la Real, Montefrío, Illora y Pinos Puente ${ }^{9}$, "Y el Rey volvió a la vega, é asentó su real cerca de donde es oy dia Santa Fé, que es cabe los ojos de Huécar, que fué a veinte é seis dias de Abril» ${ }^{10}$. Desde este primer enclave en la vega granadina «y después de estragar la tierra y asolar sus alquerías, marchó al valle de Lecrín é hizo lo mismo, matando y cautivando a sus moradores» ${ }^{11}$. Tras esta cabalgada, «(...) el Rey se vino con toda su jente hasta El Goço [Gozco], que es poco más de legua y media [8.359 m] de la ciudad de Granada y un quarto de legua [1.393 m] del río Jenil. Y allí mandó asentar su real, muy ordenado; y lo hiço cercar de cavas muy hondas, y en ellas sus puentes para las entradas y salidas de las jentes (...)» ${ }^{12}$. Para Andrés Bernáldez "Puédese contar el comienço del cerco desde veinte e seis de abril, (...), que bolvió el rey al Padul, que assentó acerca de donde está agora la villa de Santa Fee (...)» ${ }^{13}$, con lo que si creemos lo que dice este cronista, ya el 26 de abril comenzaría a asentarse el real en su localización definitiva. Como señala el erudito local Ángel Espinosa Cabezas, esta ubicación última del Real en el pago del Gozco contaba con una serie de ventajas respecto a la de los Ojos del Huécar. Por una parte una mayor salubridad, derivada de su posición más elevada y alejada del Genil, controlado en su cabecera por los granadinos, y de las surgencias de agua de los Ojos del Huécar. En segundo lugar, la protección que le otorgaba la Acequia Madre, proveniente del río Dilar (que ya estaba bajo el dominio cristiano en todo su curso), y que se emplearía para inundar los fosos del real. Y por último, una mayor cercanía al primitivo camino que unía las alquerías del Gozco y Belicena, que a su vez lo comunicaba con la fortaleza de Alhendín. Hacia poniente esta zona seguía estando bien pertrechada por el camino de Alcalá la Real, de donde provenían las recuas de abastecimiento. Para suplir el peor suministro de agua que tenía este emplazamiento, se debió de crear el hoy desaparecido Canal de Isabel la Católica, que traía el agua de la fuente del mismo nombre ${ }^{14}$.

Pese a contar con numerosos documentos que dan pistas sobre la localización del Real de la Vega, resulta difícil situarlo con exactitud sobre un territorio tan transformado a lo largo de

\footnotetext{
${ }^{7}$ Henríquez de Jorquera, Francisco. Anales de Granada. Crónica de la Reconquista (1482-1492). Edición preparada, según el manuscrito original por Antonio Marín Ocete. Estudio preliminar por Pedro Gan Giménez. Granada, 1987. p. 391.

${ }^{8}$ Pulgar, Fernando del (ca. 1430-ca. 1493). Crónica de los Reyes Católicos por su secretario Fernando del Pulgar. Cap. XCVI, p. 212, edición 1850. Documento citado por Lapresa Molina, Eladio. Santafe: Historia de una ciudad del siglo xV. Granada, 1979. p. 21, nota 45. No se indica el lugar de edición

${ }^{9}$ Espinosa Cabezas, Ángel. Santa Fe. Aproximaciones geográfico-históricas. Maracena (Granada), 1995. p. 43.

${ }^{10}$ Pulgar, Fernando del. Crónica de los Señores Reyes Católicos don Fernando y doña Isabel de Castilla y Aragón escrita por su cronista Hernando del Pulgar cotejada con antiguos manuscritos y aumentada de varias ilustraciones y enmiendas, editada por Cayetano Rosell, Biblioteca de Autores Españoles, tomo LXX. «Crónica de los Reyes de Castilla», III, Madrid, 1953, capítulo CXXXIII (o Continuación breve de Pulgar, según Juan de Mata Carriazo y Arroquía), pp. 510-511. Documento que reproduce Peinado Santaella, Rafael Gerardo. La fundación de Santa Fe (1491-1520). Granada, 1995. p. 3 7

${ }^{11}$ Eguílaz y Yánguas, Leopoldo de. Reseña histórica de la conquista del Reino de Granada por los Reyes Católicos según los cronistas árabes. Granada, 1894. p. 47.

${ }^{12}$ Santa Cruz, Alonso de. Crónica de los Reyes Católicos. Edición y estudio por Juan de Mata Carriazo y Arroquía. Sevilla, 1951. Tomo I (1491-1504), capítulos I y II, p. 31.

${ }_{13}$ Bernáldez, Andrés. Memorias del reinado de los Reyes Católicos que escribía el bachiller Andrés Bernaldez, Cura de Los Palacios. Edición y estudio por Manuel Gómez-Moreno y Juan de Mata Carriazo y Arroquía, Madrid, 1962. pp. $224-232$. Documento que reproduce Peinado Santaella, Rafael Gerardo. La fundación de Santa Fe (1491-1520). Granada, 1995. p. 326

${ }^{14}$ Espinosa Cabezas, Ángel. Santa Fe. Aproximaciones geográfico-históricas. Maracena (Granada), 1995. pp. $51-52$. $A E A$, LXXVIII, 2005, 309, pp. 23 a 43
} 
los siglos, en el que las construcciones y trazados tan efímeros que se realizaron han desaparecido por completo. Por tanto, habrá que acudir a otras fuentes gráficas que puedan suplir lo que las documentales y el reconocimiento in situ no logra precisar con claridad, unidas a la pervivencia en el territorio de estructuras que, pese a las continuas reparcelaciones y cambios de propiedad producidas en la vega granadina, puedan mantenerse en algunos de sus tramos. Tal podría ser el caso de las acequias más importantes y algunos caminos.

Para aproximarnos a la morfología original del campamento hemos consultado diversos tratados militares históricos, pues los cronistas refieren que el mismo se ordenó conforme a la práctica militar de la época. En este sentido nos ha resultado de enorme valía el Tratado de Re Militari titulado Tratado de Cauallería hecho a manera de diálogo que passo entre los illustrissimos señores Don Gonçalo Fernandez de Cordoua llamado Gran Capitan, Duque de Sella y Don Pedro Manrique de Lara, Duque de Najara (... $)^{15}$. En este tratado de 1536, su autor, Diego de Salazar, parafrasea al Gran Capitán, quien tras regresar de las campañas de Nápoles expone al Duque de Nájera su concepción del arte de la guerra. Es de sobra conocido que Gonzalo Fernández de Córdoba intervino en la Guerra de Granada, donde además de formarse destacó por sus dotes militares, adquiriendo justo renombre. En el Libro sexto del arte de la guerra, contenido en este tratado, explica e ilustra cómo alojaba en los campamentos militares levantados durante sus campañas italianas a «un exercito de veynte y quatro mil infantes, y de dos mil y quatrocientos cauallos vtiles: siendo partidos en quatro batallones» (folio 50r) (Fig. 2). Probablemente, el esquema propuesto constituya una sublimación de los reales que conoció durante la guerra granadina, lo que nos aporta una clara estructura acerca de cómo debieron de estar organizados éstos, pues "para que no nazca confusion, conuiene alojar el exercito siempre en una manera y por vna mismo forma» (folio 52v). Hemos redibujado el croquis que aparece en este libro mediante la interpretación de las medidas que se aportan (Fig. 3), obteniéndose que para alojar un ejército de estas características se precisaba una superficie de 102,95 hectáreas $(1.390 \times 1.060 \text { pasos })^{16}$. Respecto al tamaño de la hueste contenida en la vega granadina, los cronistas aportan distintas cifras, que vienen a oscilar entre los «(...) más de cincuenta mill honbres de pelea, en que avía diez mill de cavallo (...)» que dice hubo Andrés Bernáldez y los «(...) doce mill de caballo é poco menos de cient mill hombres de pié (...)» que relata el anónimo continuador de la crónica de Pulgar ${ }^{17}$. Es muy probable que la cifra estuviese más cerca del primer caso que del segundo, pues esta aproximación es mantenida a grandes rasgos por un mayor número de cronistas.

Por otro lado, en las pruebas testificales realizadas en 1550 por el morisco García el Garbi, se declara «que a los dichos vecinos que alli poblaron le dieron por termino e egido para su aprovechamiento todo el sytio que abia sydo e estado la gente del dicho Real de Sus Altezas, que hera obra de media legua de tierra en torno» ${ }^{18}$, lo que correspondería a un cuadrado de $2.786,3 \mathrm{~m}$ de perímetro y $694,6 \mathrm{~m}$ de lado, o lo que es lo mismo, una superficie de 48,25 hectáreas, para el caso de que el real tuviese una forma cuadrangular ${ }^{19}$. Tomando la declara-

\footnotetext{
${ }^{15}$ Pudimos consultar la edición en soporte digital de la Colección Clásicos Tavera. III Historia de España. Textos Clásicos sobre los Reyes Católicos. Madrid, 1999.

${ }^{16}$ Aunque si atendemos a las dimensiones generales que se refieren en el texto, sin tener en cuenta la pormenorización de medidas dadas al ir describiendo sus partes, tendríamos un campamento cuadrado de $1.500 \times 1.500$ pasos.

${ }^{17}$ Bernáldez, Andrés. Memorias del reinado de los Reyes Católicos que escribía el bachiller Andrés Bernaldez, Cura de Los Palacios. Edición y estudio por Manuel Gómez-Moreno y Juan de Mata Carriazo y Arroquía, Madrid, 1962. pp. 224232 y Continuación de la Crónica de Pulgar por un Anónimo, editada por Cayetano Rosell. Madrid, 1953. Biblioteca de Autores Españoles, tomo LXX. «Crónica de los Reyes de Castilla», II, pp. 515-516. Documentos que reproduce Peinado Santaella, Rafael Gerardo. La fundación de Santa Fe (1491-1520). Granada, 1995. pp. 326 y 329.

18 Archivo General de Simancas, 3/984/7, signatura a la que remite Eladio Lapresa Molina y que no es correcta, como comprobó Peinado Santaella, Rafael Gerardo. La fundación de Santa Fe (1491-1520). Granada, 1995. p. 63

${ }_{19}$ Para una forma rectangular, que sería la que tuviese el Real de la Vega, un perímetro constante alberga una superficie tanto menor cuanto más alargado sea el rectángulo.
} 


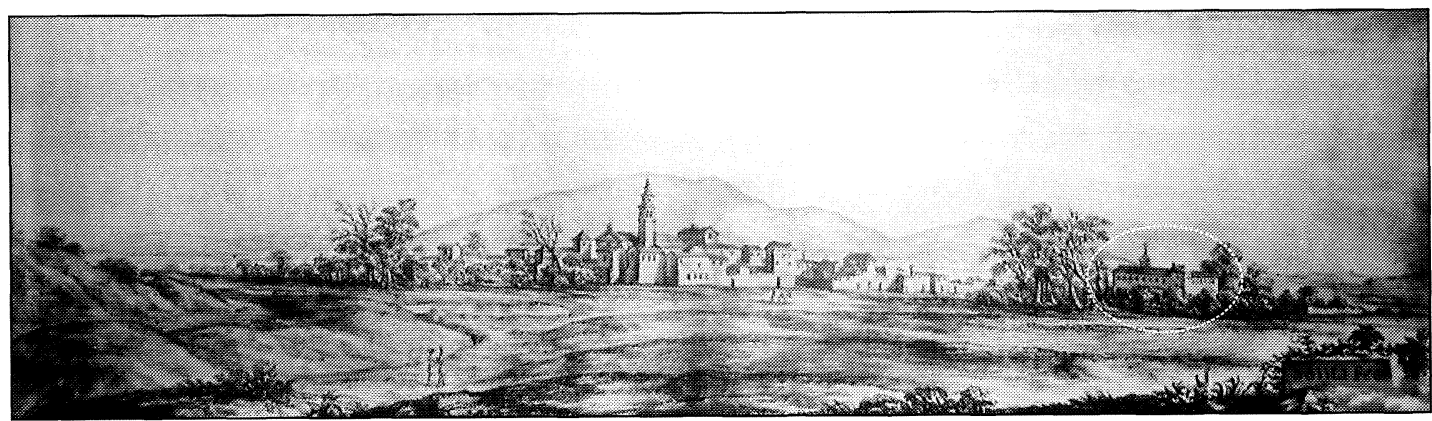

Fig. 4. Vista de Santa Fe desde el suroeste dibujada por Pier Maria Baldi en 1669 que ilustra el libro de Cosme de Médicis, Viaje por España y Portugal (1668-1669). Edición y notas por Ángel Sánchèz Rivero y Ángela Mariutti de Sánchez Rivero. Madrid, 1933, vol. II. El edificio que aparece enmarcado en una línea de puntos podría tratarse de la ermita de Santa Catalina, aún en pie en esa época.

ción de este morisco con muchas reservas, tendríamos que el Real de la Vega contaría con la mitad de superficie que los depurados campamentos militares que el Gran Capitán desarrolló posteriormente; además, el de la Vega de Granada como mínimo doblaría en número a las huestes que contenían los castros del estratega cordobés. Esto no sería de extrañar si entendemos que en el Real de la Vega las tropas se encontraban más hacinadas, como lo demuestra el hecho de que el incendio del 14 de julio de 1491 se extendiese rápida e incontrolablemente por buena parte del campamento, hecho éste del que sin duda aprendió Gonzalo Fernández de Córdoba para que no se volviese a repetir en el futuro.

Respecto a su ubicación, el dato válido más preciso sigue siendo el de la localización de la desaparecida ermita de Santa Catalina, pues por un documento de los Reyes Católicos fechado en Segovia el 7 de agosto de 1494, éstos donan «(...) a la ciudad de Santafee y sus vezinos de el sitio Real donde tubieron su asienda sus magestades: a ezepcion de 150 marjales de tierra ${ }^{20}$ de que izo grazia y merced al Real Monasterio de señor sant Geronimo desta ziudad de Granada al rededor de la Hermita de Santa Cathalina que en la dicha ziudad tenia (...)» ${ }^{21}$. Como demuestra documentalmente Eladio Lapresa Molina, esta ermita coincidía con el lugar donde tuvo su aposento la reina Isabel, pues ésta «(...) fundó en Santa Fé el convento de frailes Geronymos con el título de santa Catalina la martyr en gracias del buen sucesso que tuvo aqui el incendio de la tienda Real, y se fundó en su mismo sitio; y como enfermaron los frayles no pudieron perseverar en el, y con lincencia de la Reyna vinieron a fundar a Granada (...)» ${ }^{22}$, «(...) por haber quedado aquel sitio de la estancia del exercito inmundo y poco sano (...)» ${ }^{23}$. En la vista de Santa Fe tomada por el dibujante Pier Maria Baldi ${ }^{24}$ desde un punto al suroeste de la misma - si tenemos en cuenta la silueta de Sierra Elvira como fondo del dibujo-, se representa un edificio religioso a la derecha de la ciudad. Quizás ésta pudiese ser la ermita de Santa Catalina (Fig. 4), pues aún en ese momento se encontraba en pie. En 1705 se hundió la parte de la capilla mayor de la ermita, por lo que a continuación hubo de completarse su de-

\footnotetext{
${ }^{20}$ Casi 8 hectáreas, aproximadamente la sexta parte de la superficie hipotética del campamento.

${ }^{21}$ Archivo General de Simancas. Sala 3, legajo 781, pieza 4, traslado del siglo xviII al Archivo Real Chacillería de Granada. Legajo 1499. Documento citado por Lapresa Molina, Eladio. Santafe: Historia de una ciudad del siglo xv. Granada, 1979. pp. 209-211.

${ }^{22}$ Bermúdez de Pedraza, Francisco. Historia eclesiástica de Granada. Edición facsímil con prólogo de Ignacio Henares Cuellar. Granada, 1989. p. $174 \mathrm{v}^{\circ}$. La edición original de este libro de 1639 tiene errores en la numeración de las páginas, por lo que aparecen dos folios con este número.

${ }^{23}$ Vallejo del Burgo. Manuscrito, fol $10 \mathrm{v}^{\mathrm{o}}$. 1492. Documento citado por Lapresa Molina, Eladio. Santafe: Historia de una ciudad del siglo XV. Granada, 1979. p. 69, nota 96.

${ }^{24}$ Este dibujante acompañaba a Cosme de Médicis en su viaje por España y Portugal en 1668.
}

$A E A$, LXXVIII, 2005, 309, pp. 23 a 43 

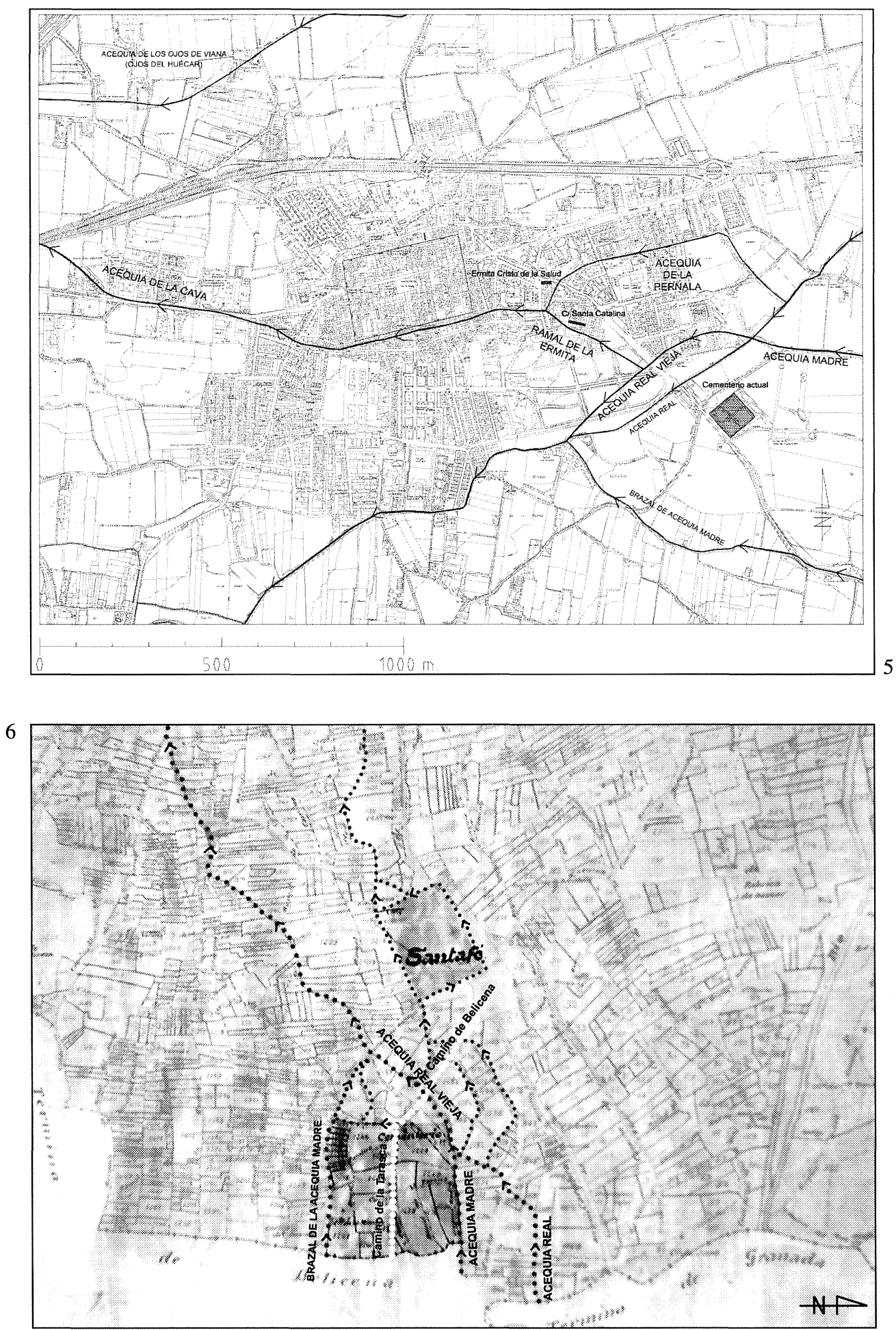

Fig. 5. Plano actual del entorno de Santa Fe donde se ha resaltado la ubicación del cementerio de la ciudad, la C/ Santa Catalina y la ermita del Cristo de la ciudad, así como el perímetro de la ciudad y el trazado de las acequias históricas, algunas de las cuales han desaparecido en la actualidad (Diputación Provincial de Granada, 2001. Escala original del plano base $1: 2.000$ ).

Fig. 6. Detalle del plano parcelario del término de Santa Fe, de 1906, sobre el que se ha indicado el sistema de acequias que suministraban agua a los Reales de la Vega y de Santa Fe. 
molición. En 1729, con motivo de la visita de Felipe V a Santa Fe que se produjo el siguiente año, los frailes reedificaron la ermita, sin embargo la iglesia «se hizo no en la parte que estaba y sí a la vista de Santafe» ${ }^{25}$. Esta nueva construcción, de la que hasta principios del siglo xx aún se conservaba el arco de entrada englobado dentro de la tapia del cortijo homólogo, debía de estar situada cerca de la calle santafesina que hoy tiene el mismo nombre, a la espalda de la ermita del Cristo de la Salud. En el Catastro de la Ensenada de 1752 aparecen inscritos 170 marjales a nombre del Monasterio de la Orden de San Jerónimo de Granada, aunque en 1835, como consecuencia del proceso desamortizador de Mendizábal, el citado monasterio fue expropiado. Quince años más tarde don Antonio Díez de Rivera, Marqués de Casablanca, adquirió en subasta las antiguas haciendas de la Orden de San Jerónimo, cediendo al Ayuntamiento de Santa Fe en 1855 quince marjales de tierra para la construcción del nuevo cementerio de la ciudad ${ }^{26}$, superficie que coincide exactamente con las dimensiones del cementerio actual de Santa Fe. No sería de extrañar que entre estos 15 marjales estuviesen situadas las ruinas de la primigenia ermita de Santa Catalina, por lo que al estar santificado el lugar, el Marqués de Casablanca lo cedería a la ciudad como camposanto (Fig. 5).

En un plano parcelario de Santa Fe de $1906{ }^{27}$ (Fig. 6) aparecen con bastante claridad las improntas aún perceptibles del Real de la Vega, en una época en la que la parcelación no estaba tan transformada como ahora. En él se pueden observar una serie de propiedades de grandes dimensiones delimitadas al norte por la Acequia Real Vieja y la Acequia Madre y al sur por un brazal de dicha acequia ${ }^{28}$. Estas parcelas se quedan a los lados del Camino de Belicena y el Camino de la Tarasca (hoy Camino de los Guacharros), que en origen constituyeron el Camino Viejo de Belicena, y que debió de funcionar como calle principal del Real de la Vega, estableciéndose las tiendas a ambos lados del mismo ${ }^{29}$. En el tablero del coro de la Catedral de Toledo en el que representa Santa $\mathrm{Fe}^{30}$, este camino podría aparecer significado por el espacio que queda entre las dos hileras de tiendas, al fondo del cual se ve Granada ${ }^{31}$ (Fig 7).

Existen otros datos documentales que nos pueden precisar esta posición del Real de la Vega, sobre todo los que se refieren a la ubicación del cementerio del propio campamento. Francisco Pizarro, artillero real que había estado en el sitio de Granada y que después se avecinó en Santa Fe, testimonió en 1532 que el camposanto guerrero lindaba «con una acequia que oy se dize del Real, e de la otra parte de la cava, el qual çimenterio esta al lado de la cava» ${ }^{32}$. La posición de la Acequia Real Vieja es conocida por el plano parcelario de1906, y la cava castrense a la que se refiere sería la que en este plano es identificada como Acequia Madre. Por otra parte Juan de Guzmán, vecino heredado en Santa Fe, decía «que vido que en el dicho sytio e çimenterio se enterravan mucha cantidad de muertos en hoyo y unos sobre

\footnotetext{
${ }^{25}$ Notas recogidas por Lapresa Molina, Eladio. Santafe: Historia de una ciudad del siglo xv. Granada, 1979. p. 59.

${ }^{26}$ Espinosa Cabezas, Ángel. Santa Fe. Aproximaciones geográfico-históricas. Maracena (Granada), 1995. p. 48.

${ }^{27}$ Este plano fue analizado por primera vez por Espinosa Cabezas, Ángel. Santa Fe. Aproximaciones geográfico-históricas. Maracena (Granada), 1995. pp. 50-51. Recientemente ha sido legado a los fondos del Centro Cultural «Damián Bayón», donde pudimos consultarlo.

${ }^{28}$ En este plano, existen dos brazales o ramales al sur de la Acequia Madre. Ambos son sensiblemente paralelos y tienen un trazado sinuoso, estando separados algo más de un centenar de metros. Nos hemos inclinado por el más meridional de ellos como posible límite sur del Real de la Vega, pues de esta manera el perímetro del recinto considerado se aproxima más a la «(...) media legua de tierra en torno (...)» referida por el morisco García el Garbi.

${ }^{29}$ Espinosa Cabezas, Ángel. Santa Fe. Aproximaciones geográfico-históricas. Maracena (Granada), 1995. p. 46.

${ }^{30}$ En lo sucesivo, nos referiremos a esta representación gráfica como tablero de Santa Fe.

${ }^{31}$ Hay que hacer notar que en este tablero, la posición del Real de la Vega se representó al noreste del Real de Santa Fe, cercana a la Puerta de Jaén o de los Carros, cuando en realidad estuvo situado al sureste del mismo. Cabría una explicación a esta incorrección por parte del autor: cuando realizó la talla en 1494 ó 1495, el Real de la Vega ya había desaparecido, por lo que trazaría sus elementos más significativos según las explicaciones dadas por alguna persona presente en el campamento durante 1491 .

${ }^{32}$ Archivo General de Simancas, 3/1375/8. Documento citado por Peinado Santaella, Rafael Gerardo. La fundación de Santa Fe (1491-1520). Granada, 1995. p. 53, nota 35.
}

AEA, LXXVIII, 2005, 309, pp. 23 a 43 

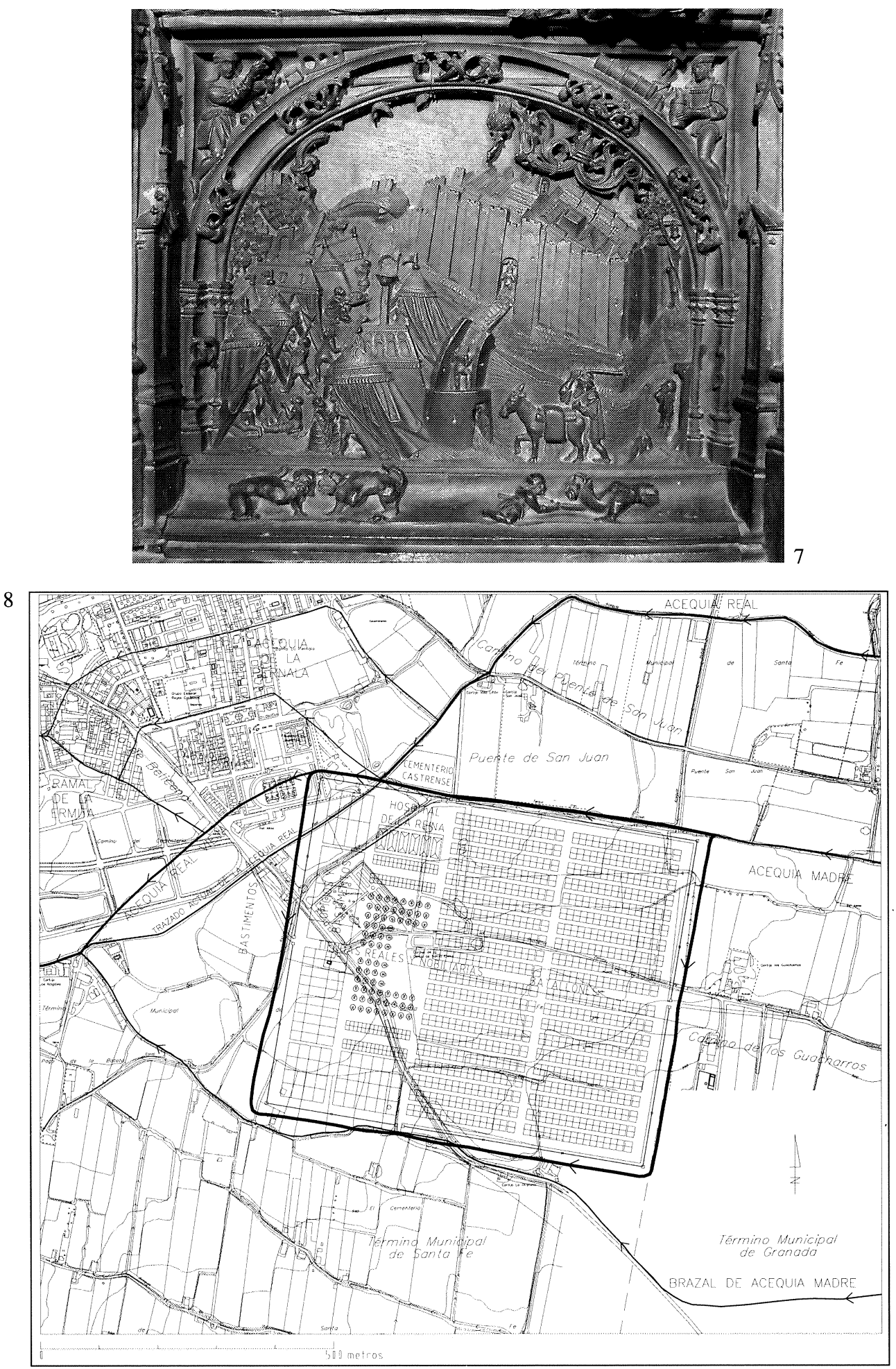

Fig. 7. Tablero del coro bajo de la Catedral de Toledo (1494-95) donde aparecen los Reales de la Vega (izquierda) y de Santa Fe (derecha) con la ciudad de Granada en último término.

Fig. 8. Hipótesis idealizada del trazado y emplazamiento del Real de la Vega dibujado sobre el plano del término municipal de Santa Fe (Diputación Provincial de Granada, 2001). Para la realización de esta hipótesis se ha tomado como base el croquis del campamento militar que aparece en el Tratado de Re Militari de Diego de Salazar (1536).

AEA, LXXVIII, 2005, 309, pp. 23 a 43 
otros, que no cabyan en el dicho çimenterio tantos muertos como heran», y el interrogatorio propuesto por el procurador Juan de Mendoza cifraba en cinco mil los enterrados, entre los cuales se encontraban «muchas personas prinçipales», aclarando que el cementerio fue consagrado por el primer arzobispo granadino y que su representado, decía cuatro misas mensuales en memoria de los guerreros difuntos. Otros declarantes concretaron que fray Juan de Ávila levantó en 1507 una ermita para el culto en este lugar, quien además dispuso en su testamento una dotación ${ }^{33}$. En los interrogatorios de un pleito de 1532 se destina el terreno de unos doce marjales $\left(6.636 \mathrm{~m}^{2}\right)$ donde estaba el cementerio del Real y la ermita de San Juan de los Reyes para ejido y prado ${ }^{34}$, ermita que debió de coincidir con la que erigió fray Juan de Ávila. Aún hoy existe un pago y un camino llamado del Puente de San Juan, ubicados en el espacio delimitado por la Acequia Real y la Acequia Madre, con lo que el cementerio castrense pudo estar ubicado en ese entorno, junto a la confluencia de ambas acequias, ocupando una superficie de unos doce marjales de tierra, como antes ha quedado expuesto (Fig. 8).

Por otro lado, sabemos que el Hospital de la Reina, el cual contaría al menos con seis pabellones o tiendas grandes, estaba junto al cementerio ${ }^{35}$, aunque, como es lógico, se encontraría dentro de la empalizada, bordeada por la cava castrense que estaría inundada por la Acequia Madre. Entre ambos reales se acotó una zona con ramales derivados de la Acequia Real que perduró después como pago de La Pernala. Quizás pudo éste haber estado dedicado a forraje para las caballerías, pues el pernal era una estaca larga utilizaba para aumentar la capacidad de carga de los montones de paja ${ }^{36}$.

Las tiendas reales y nobiliarias, así como la torre vigía de tres cuerpos que describió el cronista Pedro Mártir de Anglería, estarían situadas junto al Camino Viejo de Belicena, por donde se encuentra el actual cementerio de Santa Fe, con lo que esta zona sería el corazón de todo el Real, y a su vez el sitio más seguro del mismo, como indicaron los cronistas. Todas las tropas de infantería se formarían en batallones muy similares a los que poco más tarde desarrolló el Gran Capitán en Nápoles, ocupando la vasta llanura que quedaba al este de las tiendas reales, por frente de la ciudad de Granada (Fig. 9). El límite del campamento en esta dirección debía de llegar hasta la demarcación del término municipal de Santa $\mathrm{Fe}^{37}$. Hacia el oeste, en la retaguardia pudieron estar situados los bastimentos (provisiones para sustento del ejército, caballos, ganados...) y el personal desarmado (oficios, camareros, transportistas...), siguiendo esquemas parecidos a los propuestos por el Gran Capitán, aunque ocupando el territorio de una manera menos ordenada a como la prescribe el estratega cordobés, y quizás sin un límite muy definido.

Alonso de Palencia nos indicó que «(...) desde el principio de la campaña, había habido en el campamento ochocientos jinetes bajo el mejor jefe (...), con todo, la llegada del Cardenal [don Pedro González de Mendoza] al campamento fue de gran importancia, ya que los próceres, imitando el fervor del primado de España, aumentaron los refuerzos y en un lugar de (o delante) las tiendas de campaña, se levantó la fábrica firme de las casas y la fortificación del campamento fue aumentada (rodeada) por un terraplén y una fosa hasta los ángulos

\footnotetext{
${ }^{33}$ Archivo General de Simancas, 3/1375/8. Documento citado por Peinado Santaella, Rafael Gerardo. La fundación de Santa Fe (1491-1520). Granada, 1995. p. 56, nota 44.

${ }^{34}$ Peinado Santaella, Rafael Gerardo. La fundación de Santa Fe (1491-1520). Granada, 1995. p. 54.

${ }^{35}$ Entre otros testimonios de principios del siglo xvi, al comenzar a repartir las tierras entre los vecinos de Santa Fe, se menciona como "enpeçaron a sacar las suertes (...) e fueron derechos linde de la caua del Real fasta el cimenterio del ospital de Sus Altezas (...)». Libro de Repartimiento de Santa Fe, 32r. Documento citado por Peinado Santaella, Rafael Gerardo. La fundación de Santa Fe (1491-1520). Granada, 1995. p. 53

${ }^{36}$ Espinosa Cabezas, Ángel. Santa Fe. Aproximaciones geográfico-históricas. Maracena (Granada), 1995. pp. 57-58.

${ }^{37}$ Pues según se desprende de las declaraciones del morisco García el Garbi, los Reyes Católicos ceden todo el espacio que ocupó el Real de la Vega para el término municipal de la ciudad.
}

$A E A$, LXXVIII, 2005, 309, pp. 23 a 43 


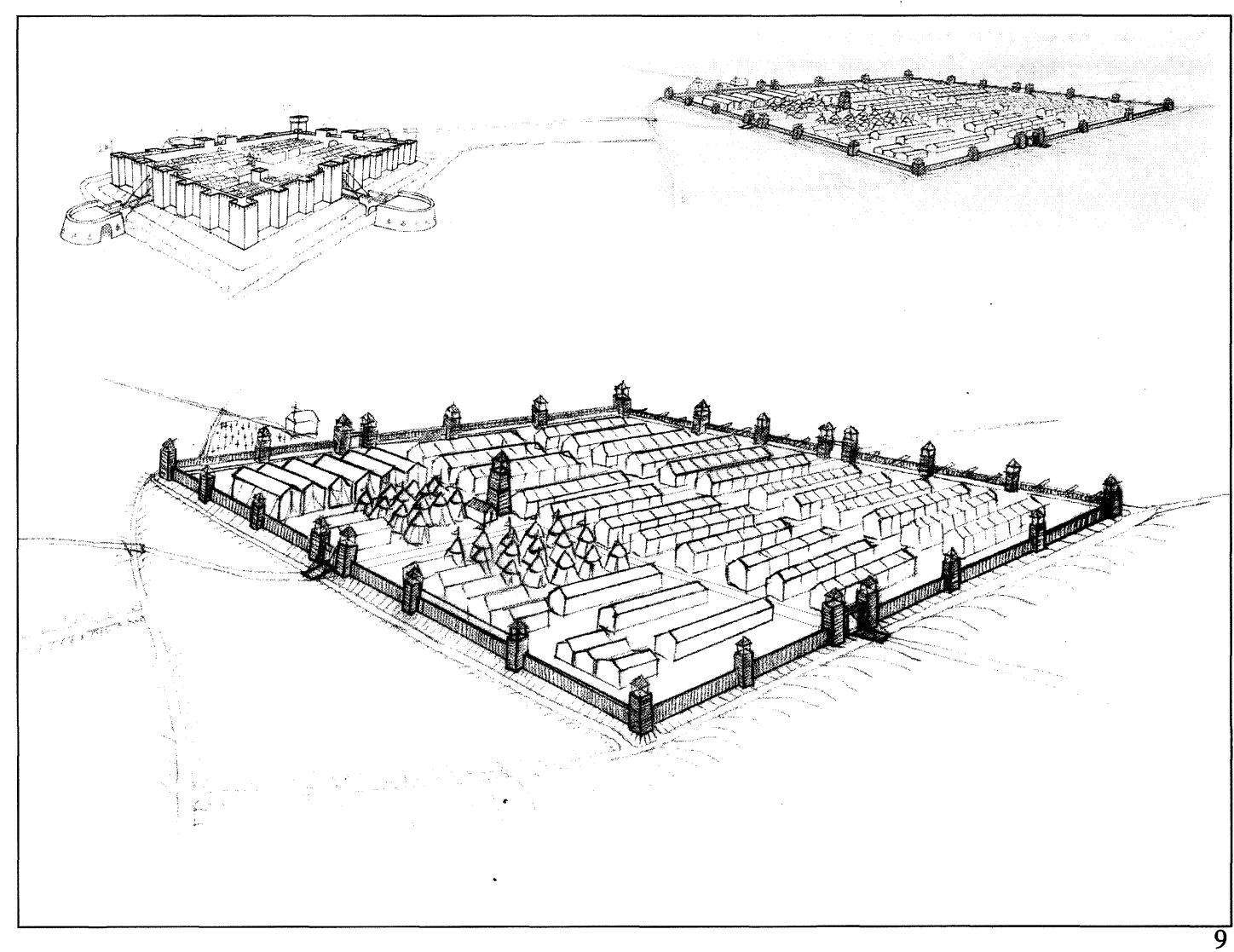

10

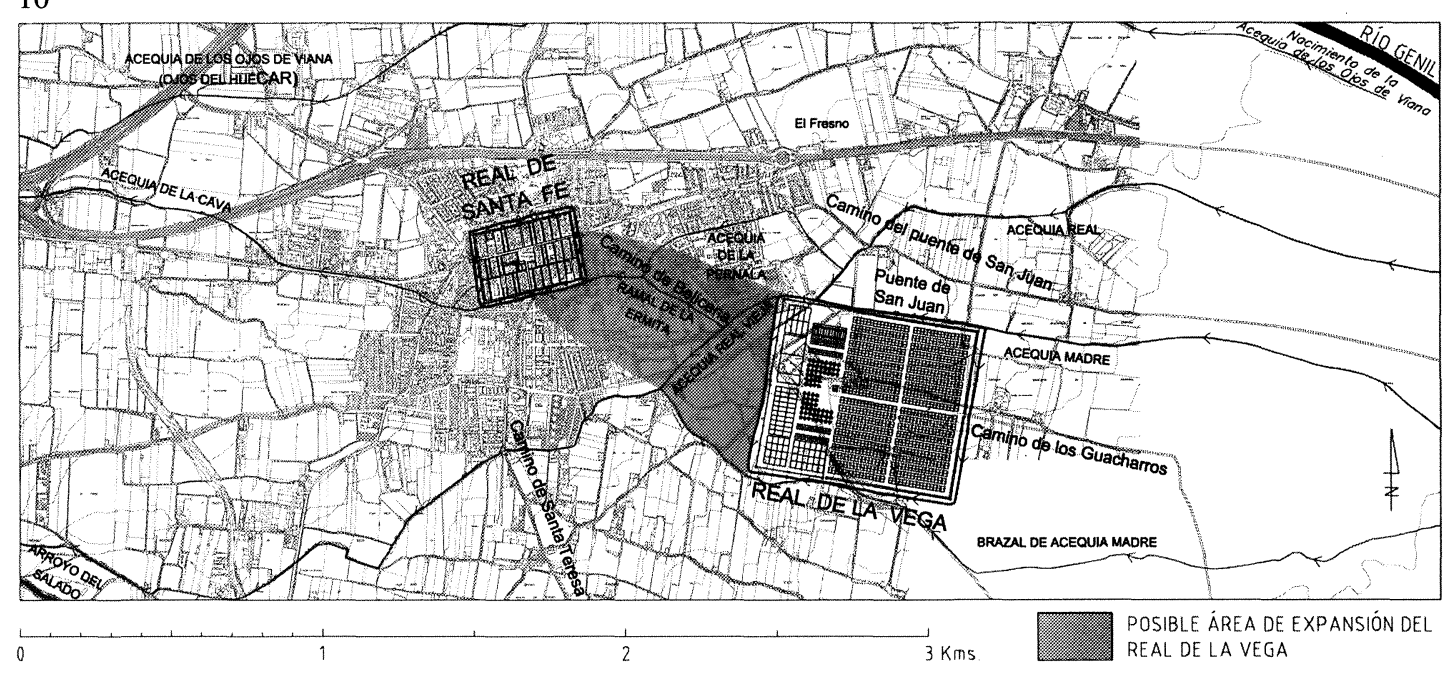

Fig. 9. Perspectiva aérea esquematizada con el trazado y la disposición hipotética de los Reales de Santa Fe (arriba izquierda) y el de la Vega (arriba derecha). Detalle del Real de la Vega (abajo). Dibujo de los autores.

Fig. 10. Plano de los emplazamientos hipotéticos del primer Real ubicado junto a los Ojos del Huécar y del Real de la Vega en relación con el Real de Santa Fe. Dibujo sobre el plano del término municipal de Santa Fe (Diputación Provincial de Granada, 2001).

$A E A$, LXXVIII, 2005, 309, pp. 23 a 43 
más próximos a la nueva ciudad» ${ }^{38}$ (Fig. 10). Con la continua llegada de tropas de refuerzo al campamento (las de la Reina, una vez se fortifica el Real de la Vega, o las aportadas por el Cardenal y otros próceres, por petición expresa de los Reyes Católicos), habría que entender su fisonomía como la de un elemento orgánico en continua evolución ${ }^{39}$. Esto coincidiría con el testimonio de otros cronistas que sitúan al Real de Santa Fe casi como una parte del Real de la Vega ${ }^{40}$, lo que también estaría avalado por una de las cuentas que recoge Gonzalo de Bae$\mathrm{za}$, quien dio fe que «Por otra çedula de su Altesa, firmada y asentada, fecha 27-XI del dicho año [1491], a Juan de la Bastida, veedor, 10.000 mrs., para comprar çierto madera, para las obras del Real de la vega de Granada» ${ }^{41}$. Por tanto, a finales de noviembre de ese año aún se seguía construyendo o ampliando el campamento.

Al oeste de Santa Fe, muy en la retaguardia de los reales, se ha conservado el nombre de un pago llamado Corral de la Reina (Fig. 11), cercano a la Acequia de la Fuente de la Reina. Ángel Espinosa Cabezas, basándose en una de las acepciones de "corral" dadas por el Diccionario de la Lengua, de Salvador Visada, que lo define como «formación de infantería parecida al cuadro moderno», supone que en este sector se establecieron las tropas de la reina Isabel, para proteger al campamento de cualquier incursión musulmana por esta zona vulnerable del río ${ }^{42}$. Sin embargo, en una cédula real de 1494, los Reyes Católicos instan a su secretario Hernando de Zafra y a fray Hernando de Talavera para que se informen «(...) de la heredad que se dize el Corral de la Reyna, que diz que es en la Vega de Granada, la qual aqui no se sabe que cosa es. Y porque nos lo queremos saber y tanbien que tierras ay en ella y lo que valee (...)» ${ }^{43}$. Este documento no deja lugar a dudas que este "corral" no perteneció a la reina católica, sino que más bien debió de estar englobado en las posesiones que la reina Zoraya tenía por estos predios, quien como sabemos por las declaraciones de algunos moriscos era la benefactora de la Alquería del Gozco ${ }^{44}$.

\section{El SISTEMA DEFENSIVo DEL REAL DE SANTA Fe}

«(...) procuraron cómo hacer junto al real y casi dentro dél una población de muy buena cerca y valuartes con sus traveses, buenas casas y todo lo demás (...), de día y de noche, hicieron los muros y torres y cavas y puertas, y otras cosas necesarias; todo dentro de ochenta días. Y así mesmo la población de casas.

\footnotetext{
${ }^{38}$ Palencia, Alonso de. Guerra de Granada. Epístola que, desde Sevilla, escribió Alonso de Palencia, el 8 de enero de 1492, a don Juan Ruiz de Medina, obispo de Astorga, para narrarle los últimos sucesos de la Guerra de Granada y la entrega de la capital (1490-1492). Estudio preliminar de Rafael Gerardo Peinado Santaella. Granada, 1998. Texto castellano, según la traducción de Eladio Lapresa Molina. Granada, 1998. pp. 93-94.

${ }^{39}$ A lo que también contribuiría el drástico y devastador incendio acaecido el 14 de julio de 1491.

${ }^{40}$ Los Reyes Católicos «(...) mandaron hacer una villa (...) para que pudiesen defensar é sostenerse junto al mismo Real é casi dentro en él (...)». Continuación de la Crónica de Pulgar por un Anónimo, editada por Cayetano Rosell. Madrid, 1953. Biblioteca de Autores Españoles, tomo LXX. «Crónica de los Reyes de Castilla», II, pp. 515-516. Documento que reproduce Peinado Santaella, Rafael Gerardo. La fundación de Santa Fe (1491-1520). Granada, 1995. p. 329.

${ }^{41}$ De la Torre, Antonio. Cuentas de Gonzalo de Baeza, tesorero de Isabel la Católica. Madrid, 1955. Tomo I: $1477-$ 1491. p. 408.

${ }^{42}$ Espinosa Cabezas, Ángel. Santa Fe. Aproximaciones geográfico-históricas. Maracena (Granada), 1995. p. 58.

${ }^{43}$ Archivo General de Simancas, Cámara de Castilla-Libros de Cédulas, libro I, folio 282. Documento citado por Peinado Santaella, Rafael Gerardo. La fundación de Santa Fe (1491-1520). Granada, 1995. p. 358.

${ }^{44}$ Los Infantes de Granada solicitaron iniciar un expediente en 1506, en el que se especificaba que el corazón de Santa Fe coincidía con la «herencia que ovo el dicho rey padre de los dichos ynfantes [Mulay-Hacem] de un onbre que se llamava Abugeila, al qual mando e dio el dicho rey a la dicha reyna, su madre [Zoraya]». Este extremo también fue ratificado por Íñigo López Maltrán, ex mayordomo de la reina Zoraya y de los Infantes. López de Coca Castañer, José Enrique. Granada en el siglo xv: las postrimerías nazaries a la luz de la probanza de los infantes don Fernando y don Juan. Granada, 1988. pp. 633 y 639. Documento que cita Peinado Santaella, Rafael Gerardo. La fundación de Santa Fe (1491-1520). Granada, 1995. p. 65.
}

$A E A$, LXXVIII, 2005, 309, pp. 23 a 43 

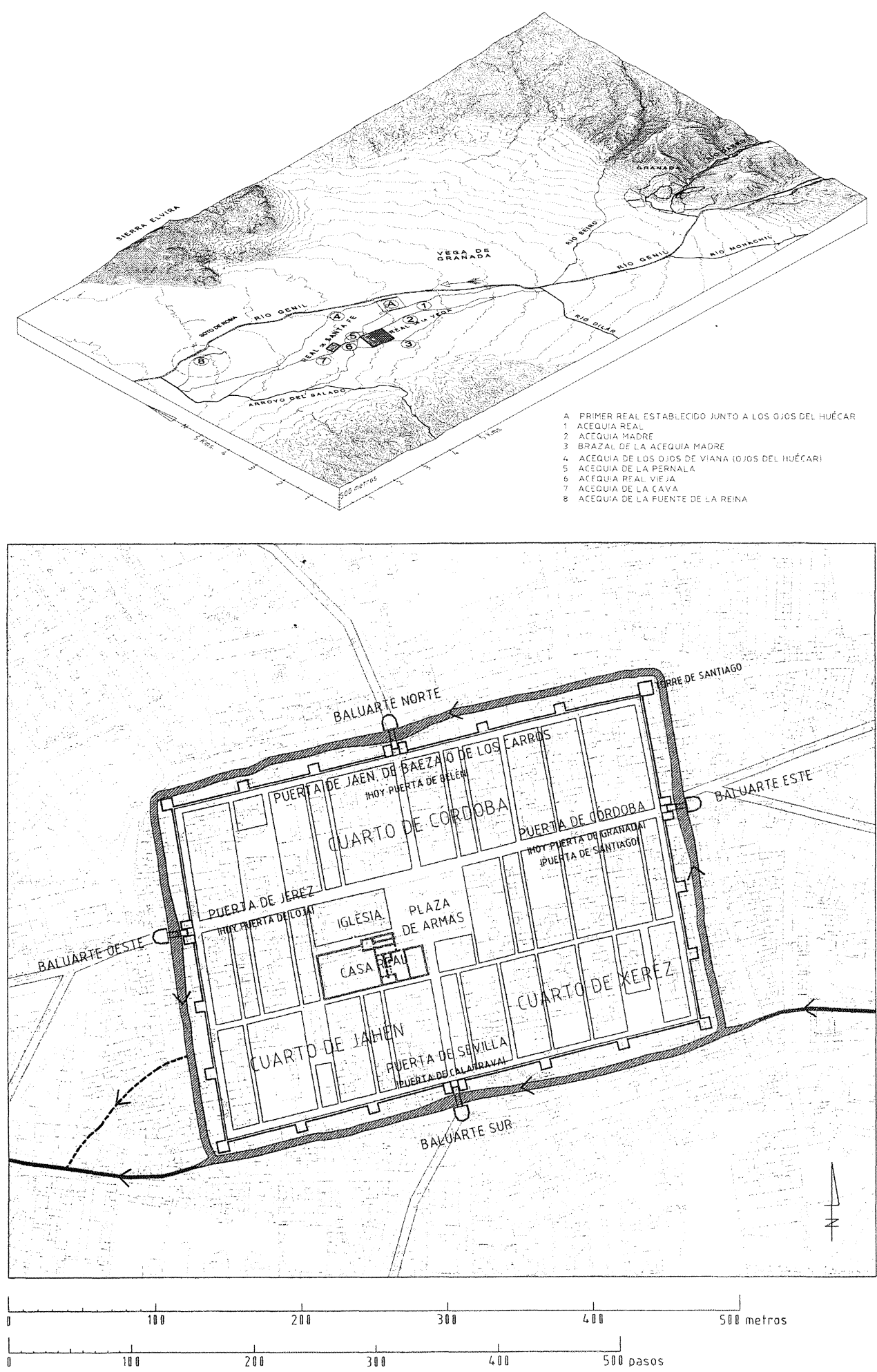

Fig. 11. Vista axonométrica del sector de la Vega de Granada comprendido entre la capital y el asentamiento de Santa Fe. Emplazamiento de los reales de las tropas cristianas con los ríos y acequias que les suministraban agua. En línea de puntos aparece enmarcada la localización del Pago del Corral de la Reina.

Fig. 13. Hipótesis del trazado del Real de Santa Fe en el que se indica su sistema defensivo y el ramal de la Acequia Real que inundaba la cava. Dibujado sobre el plano del término municipal de Santa Fe (Diputación Provincial de Granada, 2001).

AEA, LXXVIII, 2005, 309, pp. 23 a 43 
Hiçose esta población, la qual los Reyes Católicos nombraron Ciudad de Sancta $\mathrm{Fe}$, de quatrocientos pasos de largura [334,36 m] y de trecientos y doçe de anchura [260,80 m]. Y en medio de ella se hiço una muy ancha plaça, de la qual salían quatro calles prinçipales, que iban a dar a quatro puertas de la ciudad» ${ }^{45}$.

Todos los cronistas vienen a coincidir de una manera u otra que el Real de Santa Fe tenía murallas almenadas, fuertes torres, fosos (cavas), cuatro puertas de entrada y defensas, es decir, puentes levadizos protegidos por $b a$ luartes ${ }^{46}$ con sus traveses ${ }^{47}$ (Fig. 12).

Respecto a la muralla, uno de los puntos que más confusión ha generado ha venido siendo el relativo a su materialidad física: conocer la técnica constructiva que permitió levantar una cerca de 1.424 pasos (unos 1.190 $\mathrm{m})$ de perímetro en pocos meses. La hipótesis que tradicionalmente se ha venido aceptando es la que deriva del testimonio dado por Pérez de Hita en 1595, al indicar que el recinto «(...) Fué cercado de un firme baluarte [muralla] de madera todo, y luego, por cima, cubierto de lienço encerado, de modo que parecía una firme y blanca muralla, toda almenada y torreada, que era cosa de ver, que no parecía sino labrada de una muy fuerte cantería (...)», afirmación expresada como

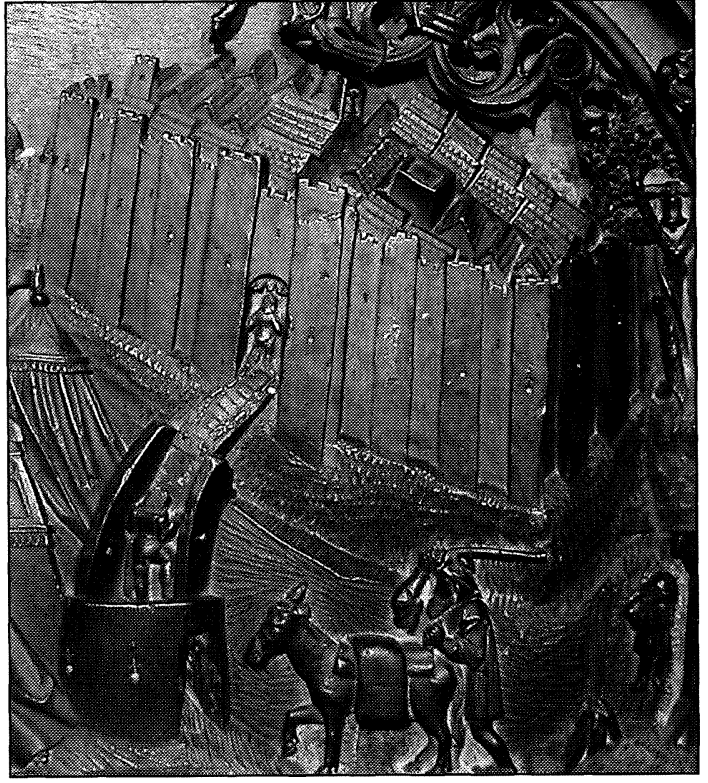

Fig. 12. Detalle del tablero del coro bajo de la Catedral de Toledo (1494-95) en el que se representan las murallas almenadas, torres, cavas, puerta de entrada con su baluarte, través y puente levadizo del Real de Santa Fe. La Torre de Santiago podría identificarse con la torre más elevada que aparece junto a la esquina superior izquierda. comentario al romance que comienza de la siguiente manera «Cercada está Santafé / con mucho lienzo encerado, / al derredor muchas tiendas / de seda, oro y brocado, (...)» ${ }^{48}$. Sin embargo, llama poderosamente la atención el hecho de que los cronistas o viajeros más o menos coetáneos a los sucesos acaecidos en 1491 traten de ensalzar la robustez y gentil hechura de los bizarros muros de Santa Fe, acaso por ser ésta una estrategia más de los monarcas para mantener en secreto sus tácticas militares. A falta de una excavación que, al menos, nos aporte información sobre la cimentación de la muralla, sólo podemos elucubrar cuál pudo ser la solución más lógica que se optó por em-

\footnotetext{
${ }^{45}$ Santa Cruz, Alonso de. Crónica de los Reyes Católicos. Edición y estudio por Juan de Mata Carriazo y Arroquía. Sevilla, 1951. Tomo I (1491-1504), capítulos I y II, pp. 37-38.

${ }^{46}$ Voz polisémica en sus inicios, en uso desde el último tercio del siglo $\mathrm{xv}$, utilizándose para denominar pequeñas fortificaciones artilladas de características indefinidas. Este baluarte a la antigua, poco tiene que ver formal y funcionalmente con el polígono irregular generalmente estrellado que sobresale en el encuentro de dos lienzos de murallas y que es propio de la fortificación abaluartada que se desarrolla a partir de la segunda mitad del siglo xvi. La voz baluarte a la que se refieren los cronistas se correspondería con la definición actual de barbacana, entendiéndose ésta como la fortificación avanzada y aislada utilizada para defender puertas de plazas o cabezas de puente, y que es atravesada por el camino de acceso, controlándolo. Mora-Figueroa, Luis de. Glosario de arquitectura defensiva medieval. Cádiz, 1994. p. 47

${ }^{47}$ Muros que unen el baluarte o bastión con la cortina o muro principal de la plaza. Cobos Guerra, Fernando. «Artillería y fortificación ibérica de transición en torno a 1500». Mil anos de fertificações na Península Ibérica e no Magreb (5001500): Actas do Simpósio Internacional sobre Castelos. Lisboa, 2001. p. 690.

48 Pérez de Hita, Ginés. Historia de los bandos de Zegríes y Abencerrajes (Primera parte de la guerras civiles de Granada). Edición facsímil. Estudio preliminar e índices por Pedro Correa Rodríguez. Edición Paula Blanchard-Demouge (reproduce la edición de 1595). Universidad de Granada, 1999. p. 280.
}

AEA, LXXVIII, 2005, 309, pp. 23 a 43 
plear. Desde luego no habría que pensar en una sólida muralla construida por entero de cantería, pues aunque el Rey Fernando ordenó al Concejo de Sevilla el 30 de abril de 1491 que «(...) para acabar mas prestamente la obra de la villa que yo mando faser junto con la çibdad de Granada son menester muchos mas bueyes e carretas, demas de los que esa çibdad ha enbiado (...)» ${ }^{49}$, no parece probable que estos efectivos se ocupasen en traer piedras de las canteras de Escúzar, La Malahá o Sierra Elvira, con la facilidad con que estos convoyes podían ser interceptados por los granadinos. Además, el hecho de que las murallas tuviesen que empezar a ser reparadas pocos años después, desapareciendo por completo en el siglo $\mathrm{XVIII}^{50}$, descarta definitivamente esta opción. Una solución de tapias de argamasa de cal similar a la de las murallas de Granada hubiese requerido también bastante tiempo para erigirlas, frente a la inmediatez que precisaba la ocasión. Por otro lado, es cierto que la madera no debió de faltar en los reales, dado que las continuas talas y saqueos de las alquerías de la Vega proporcionarían fácilmente este material de construcción, además, el cercano Soto de Roma, situado al oeste de Santa Fe, tenía aún en este momento bosques de considerable importancia. Sin embargo, no es la madera el material más idóneo para dar espesor a una muralla con gruesas y fuertes torres. Por tanto habría que acudir a una solución híbrida entre la tapiería y la empalizada de madera: bloques de tierra prensada con paja, cantos rodados y algo de cal, con un encofrado perdido a ambas caras de madera, conformado por troncos de árboles clavados en vertical ${ }^{51}$. Si a todo ello se le da un recubrimiento de cal para uniformarlo y rigidizarlo, tendríamos el «lienzo encerado» del que habla la tradición popular. Al fin y al cabo sería ésta una simplificación y aceleración de la técnica constructiva de las tapias, en la que se deja el encofrado perdido.

En cuanto a las torres defensivas, sabemos que eran de planta cuadrada o rectangular por el tablero de Santa Fe (Fig. 12) y, si creemos a Antonio de Lalaing, Señor de Montigny, quien en 1501 acompañó a Felipe el Hermoso en su primer viaje por España, Santa Fe «Tiene cuatro puertas y dieciséis torres alrededor de las murallas. Los fosos, hechos de tierra seca, son muy profundos (...)»52. Por otra parte, en el paño de muralla longitudinal del tablero de Santa Fe, la puerta de entrada aparece flanqueada por dos torres y al lado de cada una de éstas, otras dos más y la de esquina. Con ello tendríamos que en los paños de muralla longitudinales (norte y sur, de 400 pasos de longitud) habría 4 torreones, por lo que en cada uno de los transversales (este y oeste, de 312 pasos) tendrían que disponerse 2 más, para que con las 4 torres de las esquinas hubiese un total de 16 (Fig. 13). Ahora bien, en los paños de muralla transversal las puertas de entrada están descentradas, pues se sitúan aproximadamente a un tercio del paño, más cercanas a la muralla norte. Por ello, de observar esta hipótesis, deberían encontrarse los dos torreones en el paño de mayores dimensiones de estos lienzos. Ni que decir tiene que esta hipótesis ha de ser tomada provisionalmente, hasta no quedar confirmada o desmentida por otros testimonios escritos, gráficos, o por datos provenientes del campo de la arqueología. Como mínimo, las torres de las puertas contendrían las escaleras que comunicarían las calles de ronda con el adarve de guardia almenado. En todo el perímetro amurallado y baluarte representado en el tablero de Santa Fe aparecen troneras de palo y orbe o de cruz y orbe. Por

\footnotetext{
${ }^{49}$ Citado por Carriazo y Arroquía, Juan de Mata. El tumbo de los Reyes Católicos del concejo de Sevilla. Sevilla, 1971. Tomo V. p. 224. Documento que copia Peinado Santaella, Rafael Gerardo. La fundación de Santa Fe (1491-1520). Granada, 1995. p. 335.

${ }^{50}$ Espinosa Cabezas, Ángel. Santa Fe. Aproximaciones geográfico-históricas. Maracena (Granada), 1995. p. 123.

${ }^{51}$ Esta hipótesis ya fue formulada por Espinosa Cabezas, Ángel. Santa Fe. Aproximaciones geográfico-históricas. Maracena (Granada), 1995. pp. 119-120.

${ }^{52}$ de Lalaing, Antonio (Señor de Montigny). Primer viaje de Felipe el Hermoso a España en 1501. recopilación, traducción, prólogo y notas por García Mercadal, José. Viajes de extranjeros por España y Portugal: desde los tiempos más remotos hasta comienzos del siglo Xx. Valladolid, 1999. Tomo I. p. 443.
} 


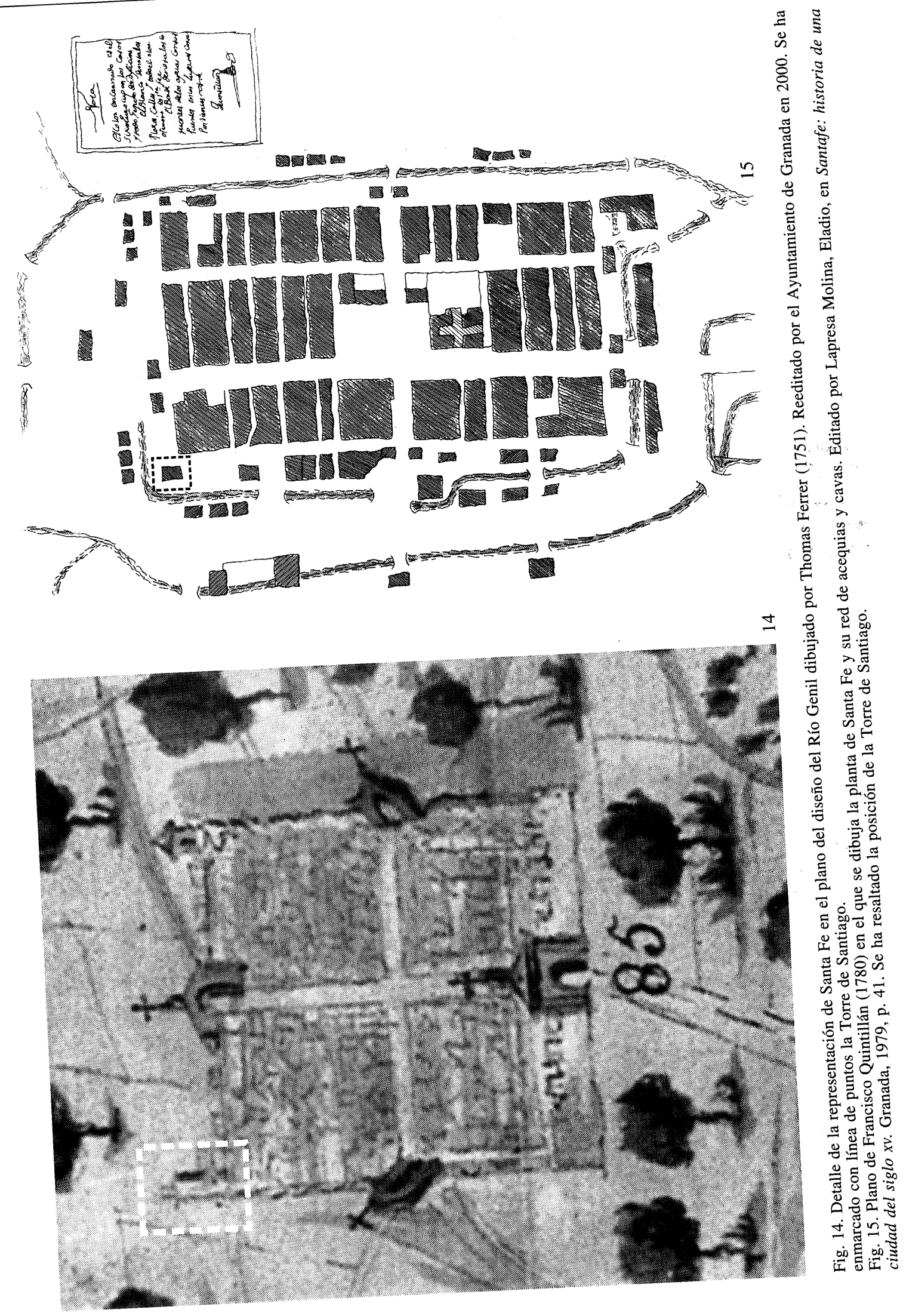

AEA, LXXVIII, 2005, 309, pp. 23 a 43 
otra parte, en el memorial sobre las condiciones de la obra que se debía de hacer en la fortaleza de Güejar Sierra, pocos años después, se indicó que sus troneras fuesen «(...) de la condición é hechura que están las lombarderas de Santa Fée (...)» ${ }^{53}$.

Una torre vigía destacaba en altura sobre las demás, la Torre de Santiago, que pudo haber recibido esta denominación por deberse su construcción al Maestrazgo de la Orden Militar del mismo nombre. En el tablero de Santa Fe esta atalaya se ubica junto a una de las torres de esquina que estaban enfrentadas a Granada (Fig. 12). El escribano Antón de la Barrera la mencionó, diciendo que estaba «(...) junto a la puerta de Córdoba [hoy de Granada] de cara a la grande e onrada cyudad de Granada ${ }^{54}$. Además, en la vista de Santa Fe tomada por el acompañante de Cosme de Médicis en 1668 no se dibujó, cuando aún se encontraba en pie, quizás por quedar tapada por la silueta de la ciudad, puesto que la vista estaría tomada desde el suroeste (Fig. 4). Por otro lado en el plano del diseño del Río Genil, de 1751, aparece dibujada una torre de esquina, singularmente alta, por lo que debe tratarse de ella, aunque en este caso se encuentra en la esquina sureste de la muralla (Fig. 14). El último testimonio escrito que tenemos de la misma, resulta ser el más explícito en cuanto a su localización. Se trata del expediente del proyecto que el 6 de noviembre de 1777 presenta el arquitecto Domingo A. Lois de Monteagudo para desagüe y saneamiento de la cava norte, donde podemos leer: «Desde la puerta que llaman de Granada hasta la torre de Santiago hay ciento y diez pasos. (...). Desde la dicha torre de Santiago hasta la placeta frente de la casa del Señor marqués de Villalegre [hoy Placeta de las Flores], que es uno de los tránsitos por donde cruza dicha cava una parte del pueblo, hay ciento y treinta pasos (...)» ${ }^{55}$. La proporción de pasos aportada ubica la torre en la esquina común a las murallas norte y este ${ }^{56}$, si le damos al paso un valor aproximado de $0,64 \mathrm{~m}$, en lugar de los 0,8359 m que medía el paso castellano del siglo $\mathrm{xv}^{57}$, medida con la que se trazó la ciudad a cordel. Esto sería posible si tenenemos en cuenta que en el siglo XvIII circulaban muchas variantes del paso o vara, según el elemento que se quisiera medir, como queda plasmado en el "Cuadro de escalas gráficas normalizadas en la Instrucción del conde de Aranda de 31 de enero de 1757" 58. Además, en el plano de Santa Fe que Francisco Quintillán realiza en 1780 para acompañar a este expediente, se dibujó un cuadrado exento en la esquina noroeste que podría ser la citada torre (Fig. 15). En otra parte del citado expediente de Lois de Monteagudo se dice que «Desde ésta [la Puerta de Loja] al torreón hay noventa pasos (...)». Esta referencia debe tomarse hacia el sur de la misma, pues en el órden lógico de la descripción que hace de la cava, trata con antelación la esquina al norte de la Puerta de Loja y la puerta en sí. Podríamos estar ante la existencia de uno de los últimos torreones de la muralla que aún se mantuvieran en pie en esta época, además, la posición donde Lois de Monteagudo lo sitúa refuerza la hipótesis de que en los paños transversales sólo existieron dos torreones.

Las cuatro puertas de entrada, pese a ser los únicos elementos de la fortificación que de alguna manera se han conservado, han cambiado su fisonomía por completo con los avatares

\footnotetext{
${ }^{53}$ Copia de un memorial é condiciones de la obra que se ha de facer en la fortaleza de Huejar. CO.DO.IN., tomo 51, pp. 120-121.

${ }^{54}$ Nota que recoge Espinosa Cabezas, Ángel. Santa Fe. Aproximaciones geográfico-históricas. Maracena (Granada), 1995. p. 123, sin indicar su procedencia.

${ }^{55}$ Archivo Municipal de Santa Fe, signatura 590/3. Transcrito por Salvador Aristondo Akarregi y publicado en el programa de fiestas local de 2001, p. 10.

${ }^{56}$ Coincidimos plenamente con D. Miguel Ángel Fernández Aparicio, quien basándose en el mismo informe, es el primer investigador que la sitúa en esta esquina.

${ }^{57}$ La medida histórica española del paso coincide con los $83,59 \mathrm{~cm}$ de la vara (que equivale a tres pies españoles). Kottmann, A. Die Kultur vor der Sintflut: Das gliche Zahlendenken in Ägypten, Amerika, Asien und Polynesien. Heiligkreuztal, 1993. Citado por Nitz, Hans-Jürgen. «Los principios de planificación en la fundación de la ciudad real de Santa Fe en Granada (1491). Una aportación al modelo de ciudad colonial española en América». Cuadernos Geográficos de la Universidad de Granada. Granada, 1997. Núm 2, pp. 111-129.

${ }^{58}$ Servicio Histórico Militar, Biblioteca Central Militar. Copiado en la Colección Aparici.
} 


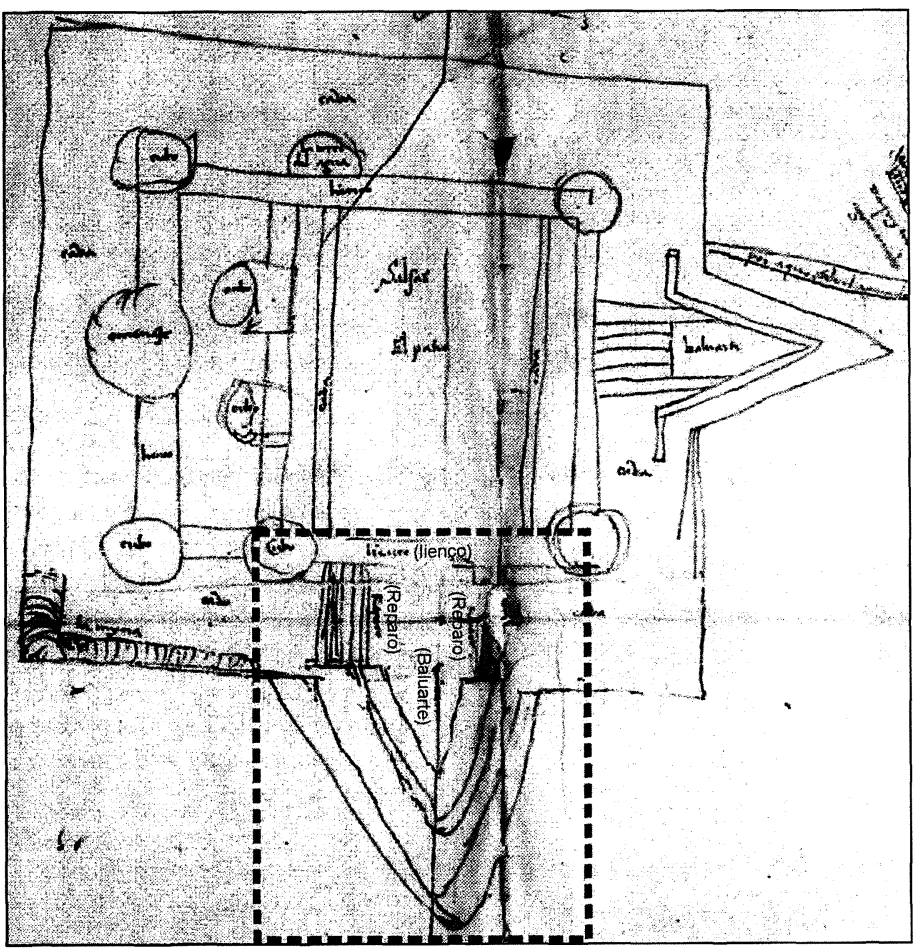

Fig. 16. Detalle de la planta de la fortaleza de Salsas durante el cerco francés realizada por el capitán Gonzalo de Ayora en 1503. RAH, CSC, A-11, f. 357. Reproducida por Cobos Guerra, Fernando, y de Castro Fernández, José Javier, en «Diseño y desarrollo técnico de las fortificaciones de transición españolas». Las fortificaciones de Carlos V. Madrid, 2000, p. 220. En línea de puntos aparece enmarcado el Baluarte de la Puerta o del Rey, volado por Ramiro López en 1503 y reconstruido más tarde. del tiempo. Fueron erigidas por los Maestrazgos de las Ordenes Militares de Santiago, Calatrava y Alcántara, quienes debieron de encargarse de la construcción del sistema defensivo de Santa $\mathrm{Fe}$, pues los concejos de las ciudades (Sevilla, Córdoba y Jaén) se ocuparon de los tres "quartos" o cuadrantes en que fue dividida la estructura urbana de la ciudad-campamento ${ }^{59}$ (Fig. 13). Todas han sufrido innumerables reparaciones, restructuraciones, expolios e incluso reedificación completa, hasta que en los siglos XVIII y XIX quedaron convertidas en pequeños oratorios dedicadas a distintas advocaciones marianas. Así, las Puertas de Sevilla y Jaén se reafirmaron en 1594, $1604,1615,1624$ y 1632 , la de Granada se hundió por un terremoto en 1698, reconstruyéndose inmediatamente, y el Arco de Loja se abatió a principios del siglo xx, siendo reedificada en $1952{ }^{60}$. El resultado es que, salvo la posición donde se encuentran y el basamento de los contrafuertes de algunos arcos (que antes eran las torres laterales a cada puerta), poco más conservan de su estado primigenio. Tampoco sabemos con certeza absoluta si la muralla entestaba en los contrafuertes de estas puertas en una posición media, como parecen indicar algunas improntas laterales muy modificadas, o si por el contrario las torres de las puertas arrancaban desde la muralla hacia el exterior, siguiendo el alineamiento actual de la calle, que es lo que resultaría más lógico. Al ser el cuerpo superior de los arcos una reinvención que nada tiene que ver con su aspecto originario, se han perdido los huecos de fachada por donde pasarían las cadenas del puente levadizo, elemento indispensable para que el foso cumpliese su función defensiva. Así aparece representado en el tablero de Santa Fe, y este detalle no es baladí, pues en las fortalezas musulmanas de los restantes tableros no se introduce este elemento. Tampoco quedan vestigios del hueco por donde bajaría el probable rastrillo que tendrían las puertas detrás de su arco de entrada.

Respecto a las cavas, cegadas las de la muralla norte y embovedadas las de la sur, aún hoy es fácil seguir su trazado (Fig. 13). Ciertas calles al norte y oeste de la ciudad que han mante-

\footnotetext{
${ }^{59}$ En el Primer deslinde y amojonamiento de Santa Fe, llevado a cabo en junio de 1492 por Antón de la Barrera, aún se denominaban Puerta de Santyago y Puerta de Calatrava presumiblemente a la Puerta de Granada y a la Puerta de Sevilla, según las referencias que se aportan en el texto transcrito por Lapresa Molina, Eladio. Santafe: Historia de una ciudad del siglo xv. Granada, 1979. pp. 187-189.

${ }^{60}$ Espinosa Cabezas, Ángel. Santa Fe. Aproximaciones geográfico-históricas. Maracena (Granada), 1995. pp. 188, 190 y 210 .
}

AEA, LXXVIII, 2005, 309, pp. 23 a 43 

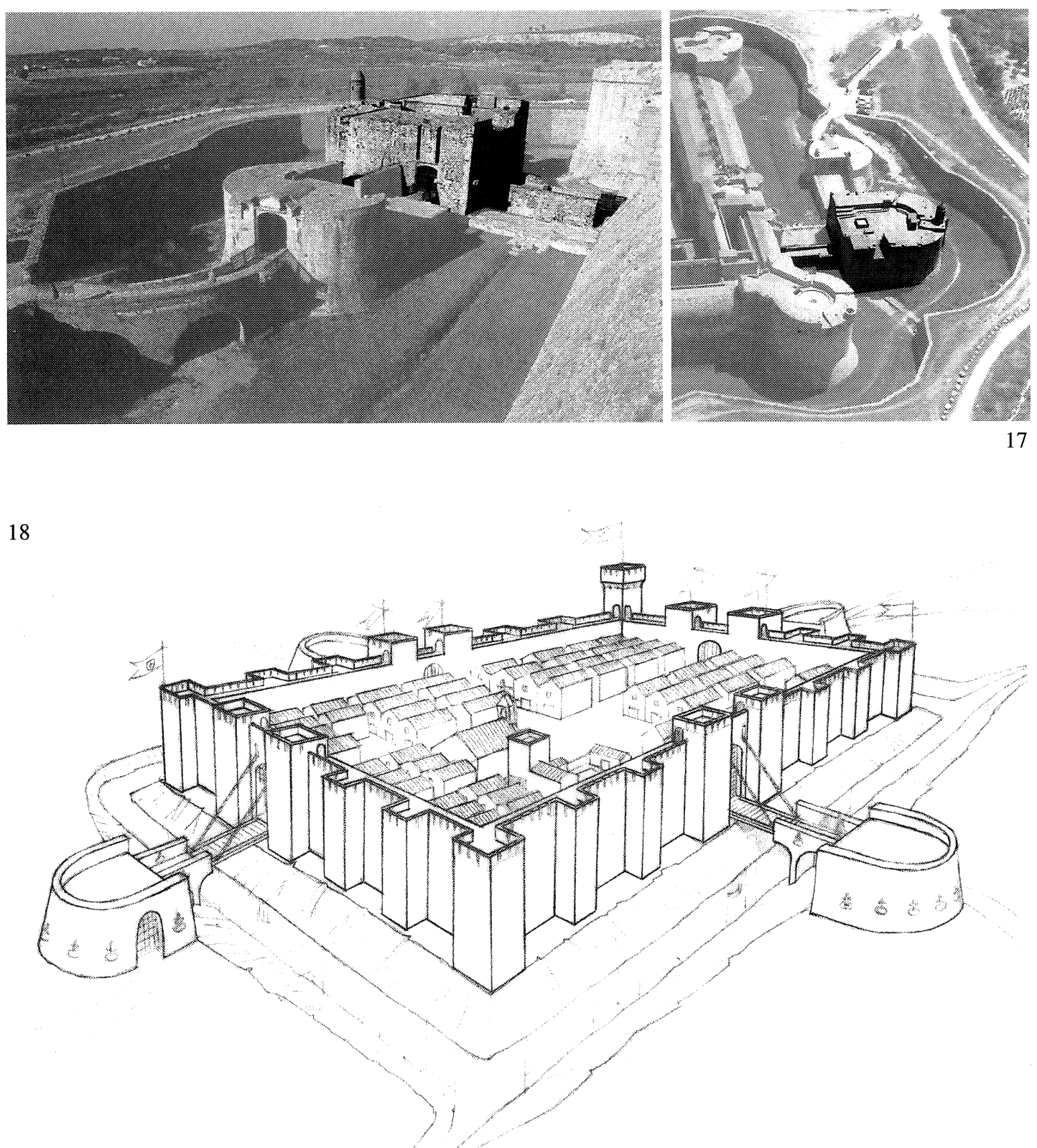

Fig. 17. Estado actual del baluarte del Rey que defendía el acceso a la fortaleza de Salsas. Izquierda: Vista aérea desde el oeste tomando como base la fotografía reproducida por Bayrou, Lucien; Faucherre, Nicolás, y Quatrefages, René, Salses Fort. Pyrénées-Orientales, París, 1998, p. 9. Derecha: Vista aérea desde el cubo sur tomando como base la fotografía de Catherine Bibollet reproducida por Truttmann, Philippe, Fort Salses. Rennes, 1996, p. 10.

Fig. 18. Perspectiva aérea idealizada con el sistema defensivo y la disposición del Real de Santa Fe. Dibujo de los autores.

nido un desnivel considerable, y otras en la parte meridional que han conservado una toponimia relativa a las cavas (C/ Hoyo, C/ Molino Herrera, C/ Darro, C/ Isla...), delatan por dónde pasaba el foso. Respecto a la sur, muchas de las casas ubicadas sobre el trazado de la muralla presentan un patio posterior donde se puede localizar el embovedado que oculta el foso inundado por un ramal de la Acequia Real Vieja. Si esto lo cotejamos con el famoso plano de Quintillán de 1780, levantado precisamente como apoyo al expediente de Lois de Monteagudo para cegar la cava norte, no resulta difícil dibujar el recorrido que debieron de seguir.

AEA, LXXVIII, 2005, 309, pp. 23 a 43 
En cuanto a los elementos que permitían el tránsito sobre la cava (Fig. 13), ya en 1502 se realizaron obras en los puentes de las Puertas de Granada y Loja; en 1508, en el de la Puerta de Sevilla, en el camino de la dehesa y en el puente del camino de Pinos Puente (partía de la Puerta de Jaén); en 1512, de nuevo en los puentes del camino de Loja, de la dehesa y del camino de Pinos y de las viñas, y varios arreglos en las puertas y torres de la villa ${ }^{61}$. Como es lógico, los puentes levadizos, traveses y baluartes que tuvo la ciudad durante su corto periodo militar (al menos en las puertas que por estar enfrentadas a Granada eran más vulnerables a un ataque musulmán) fueron sustituidos por otros pasos fijos que, salvando los fosos inundados de agua, permitiesen la libre circulación de mercancías y personas una vez que se inició el proceso de poblamiento civil de Santa Fe. En este sentido, los Reyes Católicos confirmaron el 3 de marzo de 1493 la libertad de comercio que ya disfrutaba la ciudad para su abastecimiento por un privilegio anterior ${ }^{62}$, con lo que desde primeros momentos todas estas defensas de las puertas, debieron de ser una molestia para la actividad cotidiana de la ciudad, eliminándose con prontitud.

De los baluartes citados por los cronistas, hoy sabemos no sólo que existieron (Fig. 12), sino que conocemos la autoría del ingeniero militar que los trazó. Con motivo de una carta fechada el 12 de junio de 1497, enviada por Fernando el Católico a uno de sus artilleros mayores, maestre Ramiro López, quien en esos momentos estaba destinado en el Rosellón (hoy en el sureste francés) proyectando la planta de la fortaleza de Salsas, el monarca le comentó las impresiones que le había producido la traza de la obra que se comenzaba a erigir junto a Perpiñán, que en general resultaba de su agrado. No obstante hizo a Ramiro López algunas observaciones para mejorar la propuesta, entre ellas «(...) que el baluarte de la puerta prinçipal no sea quadrado, salvo [sino] a la manera de los de Santa Fe que vos hisystes (...)» ${ }^{63}$. Este documento nos permite conocer al artífice de las defensas de las puertas de Santa Fe, que por otra parte también lo fue de los baluartes de Siete Suelos y las Cabezas en la Alhambra (1492-95), del Castillo Real de Colibre (1497-1503) o de la ciudad de Perpiñan a finales del siglo Xv ${ }^{64}$. En el plano de Salsas realizado por Gonzalo de Ayora durante el asedio llevado a cabo por los franceses en 1503 (Fig. 16), los baluartes aparecen dibujados como estructuras pentagonales, cuyas caras frontales se prolongan paralelamente a la cortina o muro principal de la plaza fuerte para cubrir los «reparos» ${ }^{65}$ que unen el baluarte con el lienzo de la fortificación. No obstante, según se deduce de la esclarecedora documentación aportada por Fernando Cobos Guerra y J. Javier de Castro Fernández en su minucioso estudio sobre la fortaleza ${ }^{66}$, poco antes del ataque francés aún «estan por labrar en los baluartes y chapa y lobera ques a cargo de maestre Pedro (...)» ${ }^{67}$. El propio capitán Ayora, en las sucesivas cartas que junto al plano mencionado envió a Fernando el Católico, relató que «el baluarte de la puerta, (...) es lo más flaco de toda la casa, (...) por no estar bien acabado él y su cara delantera (...)» ${ }^{68}$. Además faltaba por «(...) sacar de la tierra de los baluartes (...)» ${ }^{69}$, detalle que quedaba ratificado por el hecho de «que

\footnotetext{
${ }^{61}$ Peinado Santaella, Rafael Gerardo. La fundación de Santa Fe (1491-1520). Granada, 1995. p. 104, nota 103.

${ }^{62}$ Archivo General de Simancas. Registro General del Sello, folio 294. Documento citado por Peinado Santaella, Rafael Gerardo. La fundación de Santa Fe (1491-1520). Granada, 1995. pp. 344-346.

${ }^{63}$ Archivo General de Simancas, Cámara, Libro de Cédulas, número $2 / 2$, folio 105 . Agradecemos la ayuda prestada por D. Camilo Álvarez de Morales y Ruiz-Matas, quien gentilmente nos transcribió este documento.

${ }^{64}$ Cobos Guerra, Fernando. «Artillería y fortificación ibérica de transición en torno a 1500». Mil anos de fertificações na Península Ibérica e no Magreb (500-1500): Actas do Simpósio Internacional sobre Castelos. Lisboa, 2001. pp. $684,687$.

${ }^{65}$ Elemento que se pone por defensa o resguardo en una fortaleza.

${ }^{66}$ Cobos Guerra, Fernando y de Castro Fernández, J. Javier. «La fortaleza de Salsas y la fortificación de transición española». Castillos de España. Madrid, 1998. Núms. 110-111, pp. 19-30.

${ }^{67}$ Archivo General de Simancas. GA, leg 1315-127. Según Fernando Cobos Guerra y J. Javier de Castro Fernández, el citado Pedro (Çyfre) fue uno de los maestros de cantería que colaboró con Ramiro López en la obra de la fortaleza de Salsas.

${ }^{68}$ Real Academia de la Historia 9/5525.

${ }^{69}$ Archivo General de Simancas. GA, leg 1315-127.
}

AEA, LXXVIII, 2005, 309, pp. 23 a 43 
salia mucho polvo cuando le daban los tiros (...)» ${ }^{70}$. Parece ser que el dibujo de los baluartes representados en este plano se podría corresponder con obras provisionales de tierra, realizadas para proteger las fábricas inacabadas en su interior. Este baluarte inconcluso fue volado por el propio Ramiro López durante el sitio, una vez fue ganado por los asaltantes ${ }^{71}$, siendo reconstruido por él mismo entre 1503 y 1507 . Será este último el que se ha conservado, presentando planta semicircular, trayectoria desenfilada, través flanqueado por muros elevados, y puente levadizo que lo comunica con la puerta de entrada a la fortaleza, elementos básicos con que debieron de contar los de las puertas de Santa $\mathrm{Fe}^{72}$. El revellín que lo precede sería añadido por Tadino con posterioridad ${ }^{73}$ (Fig. 17).

En la evolución de la fortificación de transición española, que abarca desde los castillos de La Mota (1474-1483), Coca (1474-96) y el Alcázar Real de Carmona (1486-1488), hasta las refortificaciones que se hicieron en Salsas a partir de 1503, pasando por las barreras de cubos artillados construidas en los castillos de Salobreña y Almuñécar o los grandes baluartes de Siete Suelos y las Cabezas en la Alhambra ${ }^{74}$, deberían brillar a partir de ahora con luz propia las experiencias defensivas llevadas a cabo por maestre Ramiro López en Santa Fe, pues sus desaparecidos baluartes constituirían un claro precedente de otros desarrollados con posterioridad (Fig. 18).

\footnotetext{
${ }^{70}$ Real Academia de la Historia 9/5525.

${ }^{71}$ Cobos Guerra, Fernando y de Castro Fernández, J. Javier. «La fortaleza de Salsas y la fortificación de transición española». Castillos de España. Madrid, 1998. Núms. 110-111, p. 22.

${ }^{72}$ Entre otras diferencias, el baluarte de la puerta de Salsas tiene un esperonte triangular y una garita de ladrillo en su frente y se encuentra enclavado en el mismo foso, lo que no se manifiesta en el baluarte que aparece representado en el tablero del coro bajo de la Catedral de Toledo.

${ }^{73}$ Cobos Guerra, Fernando. «Artillería y fortificación ibérica de transición en torno a 1500». Mil anos de fertificações na Península Ibérica e no Magreb (500-1500): Actas do Simpósio Internacional sobre Castelos. Lisboa, 2001. p. 688.

${ }^{74}$ Cobos Guerra, Fernando y de Castro Fernández, José Javier. «Diseño y desarrollo técnico de las fortificaciones de transición españolas». Las fortificaciones de Carlos V. Madrid, 2000. p. 222.
} 